\title{
Syntactic Aspects in Text Messaging
}

\author{
Nancy Anashia Ong’onda \\ Department of Linguistics, Languages and Literature, Maseno University \\ P.O. Box 333 - 40105, Maseno, Kenya \\ E-mail: anashian@yahoo.com \\ Peter Maina Matu (Corresponding author) \\ Department of Linguistics, Languages and Literature, Maseno University \\ P.O. Box 333 - 40105, Maseno, Kenya \\ \& \\ Department of Language Management and Language Practice \\ University of the Free State, South Africa \\ E-mail: mainamatu@yahoo.com \\ Pamela Anyango Oloo \\ Department of Linguistics, Languages and Literature, Maseno University \\ P.O. Box 333 - 40105, Maseno, Kenya \\ E-mail: aoloo2001@yahoo.com
}

Received: December 23, 2010 Accepted: January 15, $2011 \quad$ doi:10.5430/wjel.v1n1p2

\begin{abstract}
Online interactive media such as text messaging has influenced syntactic aspects of language. In order to determine how text messaging has resulted in paradigm shift in the traditional uses of language, this paper explores the syntactic characteristics of Kenyan text messages. The discussion in this paper is structured around Coupland's Sociolinguistic theory because syntactic aspects of text messages are influenced by social factors. This theory not only aroused intense discussion within the paradigm on the nature of the discourse of Short Message Service but also steered the subsequent research theoretically and methodologically. The findings reveal that new syntactic structures have permeated into the linguistic continuum of Kenyan texters. Thus, variation analysis shows that there are instances of language (syntactic) variation at every level of English grammar. However, it is apparent that Kenyan text messages are shaped by social variables.
\end{abstract}

Keywords: Short Message Service, Kenyan, Syntactic, Variation, Use

\section{Introduction}

New technology is one of the factors that has greatly influenced human language. The mobile telephone has been the latest way to communicate quickly since the invention of text messaging. The terms 'text messaging' or just 'texting' refers to the brief typed messages sent using the Short Message Service (SMS) of mobile/cell phones, Personal Digital Assistants (PDAs), smartphones or web browsers (Thurlow and Poff, 2011). The technical restrictions of text messaging have led to the development of language short forms in SMS communication e.g. limited space (Crystal, 2001; Hard af Sagerstad, 2002; Thurlow, 2003). SMS communication allows for a reasonable use of syntactic and lexical short forms, which save character space, or touches of the handset keys, as compared with using the full forms of words (Doring, 2002: 7). Text messaging is therefore broadly defined as asynchronous text based technological mediated discourse (Thurlow, 2003; Baron, 2005) that pursues simple sentences structure for communication.

The mobile phone seems to have unique features that make it popular. For instance, the equipment is small and, eponymously, mobile; it therefore affords most texters an unobtrusive and relatively inexpensive means of communication (Habluetzel, 2007; Thurlow, 2003; Thurlow and Poff, 2011). Text messaging is also technically and 
practically restricted, allowing only 160 characters per message (Aitchison and Lewis, 2003; Thurlow and Poff, 2011). Texting thus does not always follow the standard rules of English grammar (Bush, 2005). Moreover, text messaging is a private communication which allows users to rebel against the standard rules of English language (Ong'onda, Matu and Oketch, 2010a). However, the character space limitation of the messages themselves and the cumbersome text input make the terse and otherwise rude behavior acceptable among texters (Ling, 2003).

Text messaging has been described as the "continuing assault of technology on formal written English” (Lee, 2002). Thurlow $(2006,2007)$ observes that texting impacts on literacy and standard language use, especially that of young people. Linguists and educators can therefore use the debate on text speak as a legitimate language and the breadth of its grammar, syntax and semantics to spark academic discussion and understanding of all variations of language (Daniels, 2008). Ideas on text speak can be used to promote the art of writing. For instance, Leake (2008) believes that interlocutors use abbreviations in texts in new, playful and imaginative ways that benefit literacy. Moreover, users of text speak, specifically teenagers, demonstrate very clearly that their grammatical skills are intact and they very effectively mix it with other types of language (Grinter and Eldridge, 2001; Tagliamonte and Denis, 2008). Thus text messaging is a relaxed and often at times informal mode of communication (Jansen, 2005; Thurlow, 2006).

Texting reflects language change and innovation in language. Variation within text messaging depends on the particular use of SMS (Ong'onda, 2009). The study of SMS language can therefore tell us about sentence structure and its variation in general by focusing on Kenyan text messages. Brown and Yule (1983) observe that electronic discourse has brought about new conventions in use of graphic features. Baron (1998) on the other hand predicts that participants in computer conferences would use fewer subordinate clauses and a narrower range of vocabulary and that as a result of computer communication over time, the expressive functions of language could diminish. Studies on SMS language have documented similar characteristics of text messaging (Bodomo and Lee, 2004; Bush 2005; Crystal, 2001, 2006; Doring, 2002; Grinter and Eldridge, 2001; Hard af Segerstad, 2002; Ong'onda, 2009; Ong'onda, Matu and Oketch, 2010a, 2010b; Shortis, 2007; and Thurlow, 2003). The dominant features in SMS language are the use of abbreviations, slang, syntactic reductions, asterisk emoting, emoticons, deletions of parts of speech, especially subject pronoun, preposition, articles, copula, auxiliary or modal verbs and contractions. The unique use of SMS language serves to tie the group together through the development of a common history (Ling, 2000: 18) hence users of SMS understand the use of textspeaks.

Crystal (2001, 2006) offers a comprehensive look at the linguistic features of several online communication media. Crystal, examines the linguistic conventions used in these separate media and how they differ from not only real life speech and traditional forms of writing, but also how they differ from each other, recognizing that the language of chat groups is not the only 'genre' of the internet. Herring (2001) found that with claims of structural fragmentation mediated discourse is sometimes claimed to be interactionally incoherent due to limitation imposed by computer messaging systems on turn taking. Androutsopoulos (2006) on the contrary notes that online communities generally make their social profile explicit and that language variation online is patterned by age and region. In essence language and social identity contributes to the sociolinguistics of mediated discourse.

SMS has influenced language use and linguistic variations (Ong'onda, Matu and Oketch, 2010b). There are cordial syntactic features as reflected in syntactic modifications and spelling variation in Kenyan text messages. This paper found its genus in the question: Is there a possibility that sociolinguistic factors might be affecting the users' choice of words during a specific interaction of CMC (Yates, 1995) and has anyone begun a long term study to tackle language shifts in response to recent technological change, particularly with regard to tools like Email and text messaging (Tulloch, 2003)? In reading the literature review the underlying question became apparent: What is the relationship of syntactic aspects in SMS discourse to its social context and language variation in general?

\section{Methodology}

This paper poses and addresses one broad question of how SMS language is related to its social context and how social context yields syntactic aspects. This paper falls under the scope of aputative internet linguistics (Crystal, 2005) specifically on the use of the medium itself (SMS). The research therefore deals with the lingual aspect of sociolinguistics (Weideman, 2010). Data was collected from 40 University/college students who make up the primary group utilizing text messages through a questionnaire. The goal was to collect text messages that would reflect language (syntactic) variation in SMS. A total of 160 messages were collected from the participants who were assured of anonymity and privacy of their messages thus gave the researchers the consent to analyze the messages. 


\section{Discussion}

The purpose of this paper was to analyze the syntactic aspects in Kenyan text messages. In order to demonstrate a regular relationship between social and linguistic factors, the analysis was done within Coupland's (1998) Sociolinguistic theory. Coupland argues that one position of sociolinguistic theory is that sociolinguistic theory is proper linguistic theory. Coupland further argues that sociolinguistic proper linguistic theory represents what individuals know about language. This knowledge includes acquaintance about the social distribution of forms and varieties hence variation analysis. Variation analysis depends on three factors namely, the notion of orderly heterogeneity, language change and social identity (cf. Tagliamonte, 2006). However, SMS language is underpinned with the three sociolinguistic maxims: a) brevity and speed, b) paralinguistic restitution and c) phonological approximation (cf. Thurlow, 2003).

Sociolinguistic theory was used in understanding the nature of SMS language. Thus, the analysis of syntactic aspects is based on the modification of standard norms of the structure of the sentence. Sociolinguistic variation on, the other hand, explains the reasons of the emergence of syntactic aspects.

\subsection{Syntactic aspects}

A syntactic component of grammar involves the aspect of generating grammatical structures in a language using syntactic rules (Chomsky, 1965). Variation analysis of SMS discourse shows that there are many possibilities of the syntax of the language to vary. This is especially so in the way the sentence structure is formed. The structural representation of syntactic variant is based on the assumption that variants have an identical underlying structure. Syntactic variations were found in text messages as reflected in the following ways: omission of pronouns and auxiliary verbs, omission of objects, omission of articles, omission of to infinitive, grammatical agreements, contractions and different word orders. Syntactic variation is systematically influenced by a range of factors such as the technical attributes of the mobile phone and shared background or context of the situation.

\subsubsection{Omissions}

In the analysis of the corpus of data collected through the questionnaires, syntactic variations were found as reflected in omission of pronouns and auxiliary verbs as shown in $\mathbf{M . 1}$ and $\mathbf{2}$ below.

M.1 Callin u aint picking up. Pls sms me tha eck address \& details Gdevenin.

(Iam calling you and you are not picking up. Please text me the Electoral Commission of Kenya address and details. Good evening.)

M.2 Eva known a fln smootha thn sheets of silk? eva flt the caress of silver feathers. miss u.

(Have you ever known a feeling smoother than sheets of silk? Have you ever felt the caress of silver feathers? I miss you.)

From the above messages, it is apparent that interlocutors omit personal pronouns $\mathbf{I}$ am as shown in $\mathbf{M . 1}$ and the auxiliary verbs have you in M.2 of the text message that they created which leads to syntactic variation. Users omitted pronouns and auxiliary verbs as a means of condensing the structure of language in order to save space.

Users also omitted the object of $\mathbf{M} .3$ below which is a paramount part of a transitive verb get. An object is an entity involved in the subject's performance of the verb.

M.3 Hi, hope u had a great day. Imagine sikupata.... (Hi, hope you had a great day. Imagine I did not get...)

The verb get is a transitive verb that needs an object in a sentence to make sense yet its object has been deleted. The interlocutors must be having a shared context or background knowledge of what the object of the sentence is. For instance it may be $\boldsymbol{a}$ book, $\boldsymbol{a}$ pen or money.

Another strategy that led to syntactic variation in Kenyan text messages was the omission of articles. There are two types of articles in English, indefinite $\boldsymbol{a}$ and $\boldsymbol{a n}$ or definite the. Indefinite articles $\boldsymbol{a}$ and $\boldsymbol{a n}$ refer to something not specifically known to the person one is communicating with. For instance: I saw an elephant this morning. The is used when one knows that the listener knows or can work out what particular person or thing someone is talking about. For example: Did you lock the car? However, from the data collected it was found that interlocutors omitted articles as a way of condensing the structure of the text message as shown in the M.4 below. In M.4 the definite article the is omitted from the sentence hence leading to syntactic variation.

M.4 Hi will cloz 24th. When are you coming? Ua sure drug to cure my stubborn heart.

(Hi, we will close on 24th. When are you coming? You're the sure drug to cure my stubborn heart.) 
Moreover, in terms of omission, the to infinitive was omitted in order to save time and space in the text messages that were created. An infinitive is a combination of the particle to and a verb. An infinitive can function as a noun, an adjective or an adverb. For example:

\section{To understand is easy.}

2. This is money to spend.

\section{The speaker failed to understand his audience}

In the sentences above the infinitive to understand in sentence 1 functions as a noun and is the subject of the sentence. The word easy is employed as a predicate. In sentence 2 the infinitive functions as an adjective that describes what kind of money. In sentence 3 to understand functions as an adverb that expresses how the speaker failed. The word to in M.5 is omitted yet it should accompany the verb come to form the to infinitive to come, that is, in order for it to function as an adverb as shown in $\mathbf{M . 5}$ below.

M.5 I wud like u cum tiz wkka thursade den Friday we go out.

(I would like you to come this week on Thursday, and then Friday we go out.)

\subsubsection{Contractions}

Participants in SMS communication also used contractions such as Hwz for how is and wassup for what is up as a way to condense language. A contraction is a shortened form of a word or groups of words (Ehrlich, 1987). Interlocutors contracted words by seving (cutting) the middle of a word. For instance users sever the middle of words such as birthday, nobody, come on to bday, nbody, and cmon or sever the middle of phrases for example, wev for we have, Ihv for I have, heznt for he is not. These examples illustrate that dropping the middle of a word or phrase alters the structure of the sentence. Contractions are therefore considered as syntactic variation since language is modified by deletion.

\subsubsection{Agreement}

Evidence from data analysis indicates that users' also neglected grammatical agreement between the lexemes used in the sentence structures they created. Drawing from the sociolinguistic theory, co-occurrence relationships between units may constitute the basis for defining a linguistic variable (Wolfram, 2003). Therefore, violation of grammatical agreements between lexemes in terms of number, tense, person and gender is considered as linguistic variation. For instance, the user of M.6 violates the aspect of tense which has a distinct function of marking time relations. The verb finish and miss in M.6 below ought to be in past tense finished and missed for the sentence to meet the standard norms of English language.

M.6 Baby av u maliza meeting, aki av mis u vibaya and am alone and bored. Pls kuja

(Baby have you finish(ed) meeting, really (i) have mis(sed) you badly and am alone and bored. Please come.)

M.7 Aki am sori I embarass u pls 4giv me. Ni understand.

(Really am sorry, I embarrass(ed) you please forgive me. Understand me.)

Past time seems to be the marked number of the pair in that it especially excludes the present moment (Palmer, 1999). M.6 therefore presupposes that the sender is talking about a past activity. In M.7 the verb embarrass ought to be embarrassed that is in past tense as deduced from the pragmatic act of asking for forgiveness. Nevertheless the sender of the message intentionally ignores the tense aspect that should be observed to indicate time relations in a sentence.

The discussion above shows that violation of grammatical agreement in text messages is a clear indication of emergence of a new sub-genre. It is apparent that users are aware of the English grammatical rules such as the use of pronouns, articles, the to infinitive among others but they rebel against them. Rebellion is due to 'underground communication.' Users therefore, decide to be non-official by manipulating their grammatical knowledge. Violation of grammatical agreement results to a unique language with its own norms hence making the structure of the language compressed.

\subsubsection{Word order}

Interlocutors also changed the word order of English language which led to syntactic variation. English is a subject verb object (SVO) language. However, one may change the word order if one wants to emphasize a certain point or vary the writing style. The auxiliary verb, preposition or adverb may therefore come first. For instance: For everything we do there is a conscience. The subject we has been inverted. In the corpus data collected the subject of the sentence is omitted hence leading to syntactic variation. Such sentences stand out because they have employed unusual sentence structure.

The subject $\boldsymbol{I}$ in $\mathbf{M . 8}$ below is omitted. 
M.8 Got the chapa. Thanks (I got the money. Thanks)

$\mathrm{V} O \mathrm{~V}$

M.9 Thanks, I got the cash

$\mathrm{V} \quad \mathrm{S} \mathrm{V} \quad \mathrm{O}$

The sender of M.8 lays emphasis on the verb got and the direct object the money. The sentence structure of M.8 is therefore $\boldsymbol{V} \boldsymbol{O V}$ instead of $\boldsymbol{S V O}$ since the subject of the message $\boldsymbol{I}$ has been deleted.

On the contrary in M.9 the subject $\boldsymbol{I}$ is inverted and the sentence structure is VSVO.

The sender of M.9 laid emphasis on the pragmatic act of thanking the sender by letting the word thanks to occupy the position of the subject of the sentence. The speaker's point is a key factor in the organization of the message. Inversion of normal English word order seems to be motivated by lack of paralinguistic cues such as tonal variation and word stress that accompany face-to-face communication. Due to lack of prosodic features interlocutors invert the subject of the sentence in order to emphasize on the main theme of the sentence.

\subsubsection{Abbreviations}

The use of abbreviations in sentences also indicated syntactic variation. Few text messages had abbreviated phrases. An abbreviated phrase is a phrase that has been compressed by omitting letters or by using only the first letter of each word. An abbreviated phrase is shorter than its full form. Users' formed abbreviation such as gudmo which has two words good and morning. Good drops the vowel $<\boldsymbol{o}>$ and replaces it with the grapheme $<\boldsymbol{u}>$ which entails the pronunciation of the word good. Morning on the other hand sever rning. The abbreviation lavya drops the last grapheme $<\boldsymbol{e}>$ and maintains the grapheme $\langle\boldsymbol{v}\rangle$ both of which represent the phoneme $\langle\boldsymbol{v}\rangle$ and $\langle\boldsymbol{e}\rangle$ while $\boldsymbol{y} \boldsymbol{a}$ represents the accent of the texter. Abbreviated phrases appear to be motivated by the challenge of small screen and the limited character space (Doring, 2002) and by ease of turn and fluidity of social interaction (c.f Thurlow, 2003). Moreover abbreviations are easily understood by SMS members thus fulfilling a collective identity function.

\section{Conclusion}

This paper has attempted to explicate syntactic aspects as reflected in Kenyan text messages. It was observed that new syntactic structures have permeated into the linguistic continuum of Kenyan texters. This analysis has shown that the syntactic nature of SMS is based on sentence and word modifications. Interlocutors use playful manipulation and modification that affects the syntax of the language in question. Thus, the corpus of textual data collected and analyzed demonstrates how text messaging is influencing linguistic variations hence leading to language change. The data collected shows that Kenyan text messages are compressed through omissions, abbreviations and contractions. It was also realized that SMS language is influenced by the constraints of the equipment itself. Consequently, many new linguistic variations of language beyond syntax will emerge incorporating new technology and language will continue to be adapted to meet the demands of new situations. Hence, a thorough study should determine the literacy importance of SMS language in contemporary society. 


\section{References}

Aitchison, J. \& Lewis D. M. (2003). Introduction. In J. Aitchison \& D. M. Lewis (Eds.), New media language (pp.1-3). London: Routledge.

Androutsopoulus, J. (2006). Introduction: Sociolinguistics and computer mediated discourse. Journal of Sociolinguistics, 10 (4), 419-439. doi:10.1111/j.1467-9841.2006.00286.x, http://dx.doi.org/10.1111/j.1467-9841.2006.00286.x.

Baron, N. (1998). Letters by phone or speech by other means: The linguistics of email. Journal of Language and Communication, 18 (2), 133-170. doi:10.1016/S0271-5309(98)00005-6, http://dx.doi.org/10.1016/S0271-5309(98)00005-6.

Baron, N. (2005). Discourse structures in instant messaging: The case of utterance breaks in instant messaging. In S. Herring (Ed.), Computer Mediated Conversation, Creskill NJ:Hampton Press.

Bodomo, A. B. \& Lee, C. K. M. (2004). Linguistic features of SMS texts in Hong Kong. Australian Journal of Communication, 11, 63-85.

Bush, C. (2005). Language beyond the text: txt msgs 4 a new gn8rn. The Journal of New Media \& Culture, 3(2). http://www.ibiblio.org/nmediac/summer2005/text.html. Retrieved September 12, 2007.

Brown, G. \& Yule, G. (1983). Discourse analysis. Cambridge: Cambridge University Press.

Chomsky, N. (1965). Aspects of theory of syntax. Massachusetts: The MIT Press.

Coupland, N. (1998). What is sociolinguistics theory? Journal of Sociolinguistics 2 (1), 110-117. doi:10.1111/1467-9481.00035, http://dx.doi.org/10.1111/1467-9481.00035.

Crystal, D. (2001). Language and the internet. Cambridge: Cambridge University Press.

Crystal, D. (2005). The scope of internet linguistics. Paper given Online to the American Association for the Advancement of Science meeting, February 2005. www.david.crystal.com/../Internet2.pdf. Retrieved August 18, 2010

Crystal, D. (2006). Language and the internet. Cambridge: Cambridge University Press. doi:10.1017/CBO9780511487002, http://dx.doi.org/10.1017/CBO9780511487002.

Daniels, H. A. (2008). Nine ideas about language. In V. Clark, P. Eschholz, A. Rosa, and B.S. Lee (Eds.), Language: Introductory readings, (pp. 3-20). New York: Bedford/St.

Doring, N. (2002). Abbreviations and acronyms in SMS communication. Available at: http://www.nicola-doering.de/. Retrieved August 17, 2010.

Ehrlich, E. (1987). Schaum's outlines of theory and problems of punctuation, capitalization, and spelling. New York: McGraw-Hill.

Grinter, R, E., \& Eldridge, M. (2001). “Y do tngrs luv 2 txt msg?”. In W. M. Prinz., Y. R. Jarke, K. Schimidt, \& V. Wulf (Eds.). Proceedings of Seventh European Conference on Computer Supported Cooperative Work, (pp. 219-238). ECSW 01 Germany. Dordrecht, Netherlands: Kluwer Academic Publishers.

Habluetzel, C. (2007). The remediation of love: text messaging as writing. Avenue Journal, 1(1). http://www.avenuejournal.ca/index.php/avenue/article/view/3. Retrieved September 12, 2007.

Hard af Segertad, Y. H. (2002). Uses and adaptation of written language to the conditions of computer-mediated communication. Unpublished PhD dissertation. University of Gothenburg, Sweden.

Herring, S. C. (2001). Computer mediated discourse. In D. Schiffrin and Hamilton, H., (Eds.), A handbook of discourse analysis, (pp.612-634). Oxford: Blackwell.

Jansen , E. (2005). British educators angered by texting: I say don’t get mad, get creative. http://searchwarp.com/swa4627.html Retrieved August 17, 2007.

Leake, J. (2008). Texting boosts children’s literacy. The Sunday Times, May 25. Retrieved November 24, 2010, from: http://www.timesonline.co.uk/tol/news/uk/education/article3998970.ece.

Lee, J. (2002). I think, therefore Im. New York Times, September 19, G.1 http:/query.nytimes.com/gst/fullpage.html?res=9F06E5D71230F93AA2575A C0 A9649C8B63\&sec=\&spon=\&pagewanted=all. Retrieved November $24^{\text {th }} 2010$.

Ling, R. (2000). We will be reached: The use of mobile telephony among Norwegian youth. Information Technology and 
People, 13(2), 102-120. doi:10.1108/09593840010339844, http://dx.doi.org/10.1108/09593840010339844.

Ling, R. (2003). The socio-linguistic of SMS: An analysis of SMS use by random sample of Norwegians. In R. Ling and P. Pedersen (Eds.), Mobile communications: Renegotiation of the social sphere (pp. 335-349). London: Springer.

Ong’onda, N. A (2009). Short message discourse: A sociolinguistic approach to Kenyan text messages. Unpublished M.A. thesis, Maseno University.

Ong'onda, N. A, Matu, P. M \& Oketch, O. (2010a). Kenyan electronic communication: Implication of text messaging on social interaction. US-China Foreign Language, 8(9), 1-13.

Ong’onda, N. A., Matu, P. M \& Oketch, O. (2010b). Punctuation as a sociolinguistic variable in text messages. Sino-US English Teaching, 7(9), 42-47.

Palmer, F. R. (1999). The English verb. Singapore: Longman Singapore Publishers.

Shortis, T. (2007). Gr8 txtpectations: The creativity of text spelling. English Drama Journal, 8, 21-26.

Tagliamonte, S.A. (2006). Analyzing sociolinguistic variation. Cambridge: Cambridge University Press.

Tagliamonte, S.A. \& Denis, D. (2008). Linguistic ruin? LOL!, Instant messaging and teen language. American Speech 83 (1): 3-34. doi:10.1215/00031283-2008-001, http://dx.doi.org/10.1215/00031283-2008-001.

Thurlow, C. (2003). Generation Txt? The sociolinguistics of young people's text messaging. Discourse Analysis Online, 1(1).http://extra.shu.ac.uk/daol/articles/v1/n1/a3/thurlow2002003-paper.html

Thurlow, C. (2006). From statistical panic to moral panic: The metadiscursive construction and popular exaggeration of new media language in the print media. Journal of Computer-Mediated Communication 11, 667 - 701. doi:10.1111/j.1083-6101.2006.00031.x, http://dx.doi.org/10.1111/j.1083-6101.2006.00031.x.

Thurlow, C. (2007). Fabricating youth: New-media discourse and the technologization ofyoung people. In Language in the media: Representations, identities, ideologies. In S. Johnson and A. Ensslin, (Eds.), Ed.213 - 233. London: Continuum.

Thurlow, C., \& Poff, M. (2011). Text-messaging. In S. C. Herring, D. Stein \& T. Virtanen (Eds.). Handbook of the pragmatics of CMC. Berlin and New York: Mouton de Gruyter.

Tulloch, M. (2003). Technology and language. Available at: http://www.oreillynet.com/pub/wlg/3617, retrieved $25^{\text {th }}$ Nov 2010.

Weideman, A. (2010). A framework for the study of linguistics. Forthcoming from Paideia Press.

Wolfram, W. (2003). Variation and language. In Encyclopedia of language and linguistics, Vol 2, pp.333-440. Oxford: Elsevier.

Yates, S. (1995). Oral and written linguistic aspects of computer conferencing. In S.C.Herring (Ed.), Computer mediated communication: Linguistic, social and cross-cultural perspectives pp. 29-46. Amsterdam: John Benjamins. 